\title{
ROMA HUKUKU'NDA KAYYIMLIK (CURA) MÜESSESESINE GENEL BİR BAKIŞ
}

\author{
Selda $\breve{g}$ GÜNEŞ CEYLAN*
}

Genel olarak, belli bazı hallerde bir malı idare etmek veya bir işi görmek üzere atanan kişiye kayyım denmektedir. Kayyım için ingilizce caretaker veya guardian, almanca, pfleger, ispanyolca kurator, italyanca cura, fransizca curateur, latince cura terimleri kullanılmaktadır. "Cura" latincede, tedavi etmek, iyileştirmek, geçerli hale getirmek anlamlarına gelmekteydi. Bu anlamlar çerçevesinde, Roma'da kayyımın görevlerinin, kendi gözetiminde bulunan malları hukuka uygun ve doğru bir şekilde idare etmek veya yapılan bir işlemi geçerli hale getirebilmek için, o işleme kendi onayını vermekten ibaret olduğu düşünülmekteydi.

Roma hukukunda ise, bir veya birkaç kişi menfaatine, onların mallarını idare etmek veya bu idarede kendilerine rızalarını bildirmek ve icazetlerini vermek suretiyle (consensus) yardım etmekle görevlendirilmiş kişilere kayyım denmekteydi. Roma'da ilk kayyımlar, reşit olan ancak akli melekelerini kullanamayacak durumda olan kişilere atanmaktayd $1^{1}$. Bunun yanı sıra, belli yaşı doldurarak buluğ çağına gelmiş olan kişiler, on dört yaş ve üstündekiler, kural olarak, her hukuki işlemi kendileri yapabilmekteydi. Ancak borç doğuran bazı işlemleri tek başlarına yapamamaktaydılar. Ancak kayyımlarının icazetini alarak yaptıkları hukuki işlemler geçerli olabilmekteydi ${ }^{2}$.

\footnotetext{
* Gazi Üniversitesi Hukuk Fakültesi Araştırma Görevlisi

${ }^{1}$ FAYER, Carla: La Famiglia Romana Aspetti Giuridici ed Antiquari, Parte Prima, Roma 1994, s. 559; BUCKLAND, W.W.: A Text-Book of Roman Law From Augustus to Iustinian, 2. Ed., Cambridge 1950, s. 168; ROBY, Henry John: Roman Private Law in Times of Cicero and of Antonines, New Jersey 2000, s. 121; KASER, Max: Roman Private Law (Translated by: Rolf DANNENBRING), Durban 1965, s. 275; ÇELEBICAN, Özcan: Roma Hukuku, Ankara 1997, s. 217

${ }^{2}$ HUVELIN, Paul: Cours Élémentaire de Droit Romain, Paris 1927, s. 390.
} 


\section{I - XII Levha Kanunlarında Kayyımlık ve Kayyımın Atanması}

XII Levha Kanunu'ndan itibaren akıl hastalı̆̆ı ve müsriflik fiil ehliyetini kısıtlayan sebeplerden sayılmaktaydı. Roma hukukunda, akıl hastalığ 1 , müsriflik nedenleriyle ve kural olarak on dört yirmi beş yaş arasındaki küçüklere kayyım ataması yapılmaktayd ${ }^{3}$. Ancak, bu üç durum dışında; bir harp esirinin mallarının idaresi, borcunu ödemeyen acizin mallarının idaresi, henüz iktisap edilmemiş bir terekenin idaresi, kişinin mallarını idare edemeyecek derecede hasta veya yaşlı (cura debilum personarum) olması gibi bazı hallerde de kayyım ataması yapilabilmekteydi ${ }^{4}$.

Kayyım atanmasındaki amaç, kişinin malvarlı̆̆ının zarara uğramamasını sağlamaktı. Kanunen en yakın agnatik hısım kayyım olarak atanırdı. Ancak, en yakın agnatik hısmın bulunmaması halinde, magistra kayyımı tayin ederdi. Bazı durumlarda, aile evladının da babasına, kayyım olarak atanması mümkündü 5 .

D. 27. 10. 16., Tryphoninus (Disputationum, lib. 13)

"Si furiosi puberi quamquam maiori annorum viginti quinque curatorem pater testamento dederit, eum praetor dare debet secutus patris voluntatem."

"Eğer bir aile babası, yirmi beş yaşından büyük bir akıl hastası için, yaptığ 1 vasiyetname ile bir kayyım atayacak olursa, praetor, aile babasının isteğine uyarak bu kayyımı atayacaktır."

Bir kişinin, ölüme bağlı tasarrufla kayyım tayin etmesi mümkün olmamakla birlikte, eğer bu şekilde bir istekte bulunulmuşsa, magistra genellikle bu isteğe uyardı. Ancak seçilen agnatik hısmın, kayyımı ı̆a uygun bir kişi olmaması hallerinde, praetor malların idaresi için bir başka kişiyi kayyım atayabilirdi ${ }^{6}$.

D. 27. 10. 13., Gaius (Edictum provinciale, lib. 3)

"Saepe ad alium e lege duodecim tabularum curatio furiosi aut prodigi pertinet, elii praetor administrationem dat, sciliet cum ille legitimus inhabilis ad eam rem videatur."

\footnotetext{
${ }^{3}$ Constantinus bir emirname ile yirmi yaşını tamamlamış erkeklere ve on sekiz yaşını tamamlamış kızlara, hükümdar tarafından ehliyet tanınabileceğini kabul etmişti. UMUR, Ders notlar, s. 203; SCHULZ, Fritz: Classical Roman Law, Oxford 1969, s. 197; LEE, R.W.: The Elements of Roman Law, London 1946, s. 89; TALAMANCA, Mario: Istituzioni di Diritto Romano, Milano 1990, s. 170.

${ }^{4}$ SOHM, s. 492.

${ }^{5}$ D. 27. 10. 1. 1., Ulpianus (Sabinum, lib. 1)

${ }^{6}$ ROBY, s. 121.
} 
"Genellikle akıl hastası olanların gözetimi, XII Levha Kanunlarına göre, bir kişiye verilir, ancak seçilen agnatik hısmın görev için yeterli olmaması hallerinde, praetor idareyi başka bir kişiye verebilir."

\section{II - Kayyımlığın çeşitleri \\ 1) Cura Furiosi}

Roma Hukukuna göre akıl hastaları, fiil ehliyetinden tamamen mahrumdular. Akıl hastaları için atanan kayyımlara cura furiosi denmekteydi ${ }^{7}$. XII Levha Kanunu'ndan beri akıl hastası olan kişilerin hukuki işlemleri kayyım tarafından idare edilmekteydi. Akıl hastalığıyla birlikte kişinin fiil ehliyeti ipso iure, yani kendiliğinden ortadan kalktığ kayyımın atanabilmesi için Roma Hukuku'na göre ayrı bir hacir kararı alınmasına gerek yoktu ${ }^{8}$. Bu durumdaki kişilere, en yakın agnatik hısmı kayyım olarak atanırdı. Akıl hastalarına kayyım atanmasındaki amaç, kişinin malvarlığının zarara uğramamasını sağlamaktı. Kayyım, atandıktan sonra, bir teminat göstermek ve gözetimi altında bulunan akıl hastasının mallarının bir listesini çıkarmak zorundaydı. Böylece gözetim altında bulunan kişinin zarar görmesi halinde, bu zararlar kayyımın gösterdiği teminattan karşıllanabilecekti ${ }^{9}$.

Roma'da iki tür akıl hastası olduğu kabul edilmekteydi. Furiosus terimi, akıl hastası olmakla birlikte daimi olarak akli melekelerini kullanmaktan mahrum olmayan kişiler için kullanılmaktaydı. Daimi olarak akıl hastası olan kişilere ise, mente captus veya demens denmekteydi ${ }^{10}$. Bu kişilerin mutlak ehliyetsiz oldukları düşünülmekteydi. Geçici akıl hastalarının ise, normal oldukları durumlarda (lucida intervalla) yaptıkları hukuki işlemlerin geçerliliği tartışmalı idi. Ağırlıklı görüş ise, bu kişilerin normal olarak hareket ettikleri durumlarda fiil ehliyetlerinin bulunduğu kabul edilmekteydi" ${ }^{\prime \prime}$. Bunun yanı sıra, kayyım olarak belirlenmiş birden fazla agnatik hısmın olması halinde, praetorun, hangisinin yetkili olduğunun belirlemesi gerekliydi.

D. 26. 7.3.pr., Ulpianus (Edictum, lib. 35)

\footnotetext{
${ }^{7}$ FAYER, s. 559; SOHM, Rudolf: The Insttutes (Translated by: James Crawford LEDLIE), 3. Ed., Oxford 1907, s. 492; VOCI, Pasquale: Istituzioni di Diritto Romano, Milano 1996, s. 101; Gaius 3. 106; BETTI, Emilio: Istituzioni di Diritto Romano, Vol.: 1, 2. Ed., Milano 1942, s. 70; SCHULZ, s. 197; HUVELIN, s. 390; BUCKLAND, s. 168; TALAMANCA, s. 171.

${ }^{8}$ UMUR, Ziya: Roma Hukuku Lügatı, İstanbul 1983, s. 52.

${ }^{9}$ KASER, s. 277; C. 5. 70. 7. 5a.; BONFANTE, Pietro: Corso di Diritto Romano, Vol.: 1, Milano 1963, s. 645 .

${ }^{10}$ UMUR, lügat, s. 78; VOLTERRA, Edoardo: Corsodi Istituzioni di Diritto Romano, Roma 1995, s. 128.

"KOSCHAKER, AYİTER, s. 93; VOLTERRA, s. 128.
} 
"Si plures curatores dati sunt, Pomponius libro sexagesimo octavo ad edictum scripsit ratum haberi debere etiam quod per unum gestum est."

“Pomponius, Edictum'un altmış sekizinci kitabında yazdı̆̆ına göre, eğer birden fazla kayyım atanırsa, idare için praetor tarafından içlerinden birinin onaylanması gerekir."

\section{2) Cura Minorum}

Küçüklerin, erkeklerde on dört, kızlarda ise on iki yaşını doldurmaları ile buluğ çağına girdikleri kabul edilmekteydi. Buluğ çağı öncesinde küçüğe yaptı̆̆ $\breve{1}_{1}$ lemlere onay vermek üzere bir vasi atanırken, buluğ çağı ile yirmi beş yaş arasında bulunan küçükler (puberes minores) için cura minorum denilen bir kayyımın atanması uygun görülmekteydi ${ }^{12}$. On dört yaş ile yirmi beş yaş arasındaki küçüklerin yaptıkları hukuki işlemlerin geçerli olabilmesi için kayyımın onayı gerekliydi.

Cura minorum ilk olarak ikinci yüzyılda, Marcus Avrelius zamanında kurumsallaşmışı ${ }^{13}$. Uygulamada her puberes minoresin bir kayyımı bulunmaktaydı. Ancak, imparatorun tanıdığı bir imtiyaz hakkı ile 25 yaşına gelmemiş olan küçük, reşit sayllabilirdi ki bunlara venia aetatis ${ }^{14}$ denmekteydi. Constantinus'un bir emirnamesine göre, yirmi yaşında bir erkek veya on sekiz yaşında bir kız, dürüst, ahlaklı ve mallarını idare edebilme ehliyetine sahip olduklarını ispat ettikleri takdirde, imparator tarafından reşit sayılmaktaydılar ve bu kişiler için, kural olarak, kayyım atanmasina gerek bulunmamaktayd $\mathbf{1}^{15}$.

On dört yaşından küçüklere, kural olarak bir vasi atanmaktaydı. Akıl hastalarına ise, kayyım (cura) atanırd ${ }^{16}$. Ergenlik yaşına henüz gelmeyen küçük akıl hastası ise, ona vasinin mi yoksa kayyımın mı atanmasının doğru olacağı sorununa Digesta'da açıklık getirilmişti. Buna göre, küçüğe vasinin atanabildiği durumlarda, akıl hastası olması nedeniyle kayyım atanmasına

${ }^{12}$ UMUR, Lügat, s. 52; SOHM, s. 492; VOCI, s. 101; BETTI, s. 71; BURDICK, William: Principles of Roman Law, New York 1938, s. 272; GÜNAL, Nadi: Roma Hukuku'nda Varolmayan Bir Borcun İfası Nedeniyle Sebepsiz Zenginleşme (Condictio Indebiti), Ankara 1996, s. 93; HUVELIN, s. 397; TALAMANCA, s. 172; LEE, s. 89.

${ }^{13}$ KASER, s. 275.

${ }^{14}$ KOSCHAKER, Paul, AYITTER, Kudret: Roma Hususi Hukukunun Ana Hatları, Ankara 1975, s. 92; BONFANTE, s. 661.

15 UMUR, Lügat, s. 221; THOMAS, J.A.C.: The Institutes of Iustinian, Oxford 1975, s. 57; LEE, s. 90; DI MARZO, Salvatore: Roma Hukuku (Çeviren: Ziya UMUR), İstanbul 1954, s. 202; C. $2.44 .1-4$.

${ }^{16}$ ARANGIO-RUIZ, s. 495; BETTI, s. 65; BORKOWSKI, s. 148; Nuovo Dizionario di Giuridico Romano, s. 146; VOLTERRA, s. 128; UMUR, Roma Hukuku, s. 201; AYİTER, s. 88; BONFANTE, s. 661; LEE, s. 89; Iust. Ins. 1. 23. 
gerek yoktu. Akıl hastası olan küçük henüz ergenlik çağına ulaşmadığ1 için vasisi tüm işlerini görmekle yetkiliydi ${ }^{17}$.

\section{26.1.3 pr., Ulpianus (Sabinus lib. 37):}

"Qui habet tutelam pupillus uel pupilla si furere coeperint, in ea causa sunt, ut in tutela nihilo minus durent: quae sententia Quinti quoque Muci fuit et a Iuliano probatur eoque iure utimur, ut cesset cura, si tutelae aedas indigeat."

"Vesayet altındaki küçük, akıl hastası olacak olursa, Quintus Mucius'a göre ve Iulianus'un da onayladığı kadarıyla biz de aynı kurala uyarak diyebiliriz ki, küçüğün vesayet atanmayı gerektirecek yaşlar arasında olması halinde, akıl hastası olduğu için kayyım atanmasına gerek yoktur."

On dört yaşından küçük ve vasisi bulunanlara da isteğe bağlı olarak, istisnai durumlarda, danışman statüsünde kayyım atanabiliyordu. Vasinin küçüğe karşı veya küçüğün vasiye karşı dava açtığı durumlarda, vasi ile küçük karşı karşıya geldiğinden bir çıkar çatışmasının olması normaldi. Bu halde, atanan kayyım küçük adına işlemlerde bulunurdu ${ }^{18}$. Ayrıca, küçüğün malvarlığını çok geniş olması nedeniyle, vasi kendisine yardım etmek üzere, küçüğün işlerinde danışmanlık yapacak bir kayyımın atanmasını talep edebilirdi ${ }^{19}$.

Iust. Ins. I. 21.3.

"Si inter tutorem pupillumve iudicium agentum sit, quia ipse tutor in rem suam auctor esse non potest, non praetorius tutor ut olim constituitur, sed curator in locum eius datur, quo interveniente iudiciumperagitur et eo peracto curator esse desinit."

"Vasi ile küçük arasında dava açılacak olursa, vasi kendisine ait bir iş için auctoritas'ını veremeyeceğinden, praetor tarafından küçüğe, eskiden olduğu gibi bir vasi değil, onun yerine bir kayyım verilir. Bu kayyım davaya müdahale eder ve davanın nihayetinde kayyımlı̆̆ sona erer."

Lex Plaetoria ${ }^{20}$ ile kabul edilen küçükler üzerindeki kayyımlık ile, henüz yirmi beş yaşını tamamlamamış olan küçüklerin hukuki işlemlerini yapabilmelerine bir kontrol getirilmiş olmaktaydı. M.Ö. 192-191 yıllarında çıkarıldığı düşünülen lex Plaetoria ile küçüğe, kayyımının bulunmaması halinde, yaptığ exceptio legis Plaetoria hakkı verilmekteydi. Bu yaşlar arasında bulunan küçükler, tecrübesizlikleri yüzünden kolaylıkla aldatıldıkları için, yaptıkları

\footnotetext{
${ }^{17}$ D. 26. 1. 3.pr., Ulpianus (Sabinum, lib. 37)

${ }^{18}$ D. 27.3.9. 4., Ulpianus (Edictum, lib. 25) ; C. 5.44.

19 ROBY, s. 122; D. 26. 7. 3.4., Ulpianus (Edictum, lib. 35)

20) Lex Plaetoria, bazı kaynaklarda da lex Laetoria olarak geçmektedir. KASER, s. 275; UMUR, lügat, s. 122; TALAMANCA, s. 173; ROBY, s. 123; HUVELIN, s. 398.
} 
işlemler, praetorun lex Plaetoria ile verdiği yetkiye dayanarak hükümsüz kabul edilebilmekteydi ${ }^{21}$.

Bir başka ifade ile, kayyımı olmayan küçük, bir borç altına girmiş ve kendisine dava açılmışsa, bu def'iyi ileri sürerek, küçük olduğu ve aldatıldığı iddiası ile, davayı hükümsüz bırakabiliyordu. Ancak, eğer küçük işlemden bir zarar görmüşse, işlem geçerli kalmakla birlikte, diğer tarafa bir ceza verilmekteydi. Ayrica, praetor, yaptığı hukuki işlemden zarar gören küçüğe, Klasik Dönem'de bir sene, Iustinianus Dönemi'nde ise üç sene zarfında, yaşının küçüklüğü sebebiyle aldanmış olduğunu ileri sürebileceği bir in integrum restitutio ob aetatem (eski hale getirme) hakk1 vererek, işlemi iptal etmesi imkanını sağladi ${ }^{22}$. Bu nedenle, kanunun bu hükmünden kurtularak tam ve geçerli işlem yapmak isteyenler, kendilerine bir kayyımın atanmasını istemekteydiler.

M.S. 3. yüzyıldan itibaren, on dört yirmi beş yaş arasındaki her küçüğe bir kayyım atanmaya çalışılmaktaydı. Iustinianus Dönemi’nde ise, yirmi beş yaşından küçük olanlara kayyım tayini mecburi hale getirildi. Bu kişilerin kendilerinin talepte bulunmamaları halinde, magistra onlar için kendiliğinden kayyım atayabiliyordu ${ }^{23}$.

\section{3) Cura Prodigi}

Roma'da müsrif, babasından kalan mirası israf eden ve bu sebeple ailesinin maddi varlığını tehlikeye düşüren kişiye denmekteydi ${ }^{24}$. Müsriflerin babalarından kalan, ab intestato ${ }^{25}$ (kanuni mirasla) elde ettikleri malların kontrollü olarak harcanması için, bu kişilere kayyım atanırdı. XII Levha Kanunu'ndan beri, mirasçılarına zarar verecek şekilde mallarını harcayan müsrifler (prodigus) magistra kararı ile, hacir altına alınarak (interdictio), malları bir kayyım vasıtası ile idare edilirdi ${ }^{26}$. Müsriflere kayyımın atanabilmesi için, günümüz hukuk düzenlerinde olduğu gibi, hacir kararının alınması gerekliydi. Hacir kararı alındıktan sonra, en yakın agnatik akraba kayyım olarak atanırdı.

\footnotetext{
${ }^{21} \mathrm{VOCl}, \mathrm{s} .10$; THOMAS, s. 57.

22 LEE, s. 89; UMUR, Lügat, s. 87; DI MARZO, s. 201; ERDOĞMUŞ, Belgin, TAHIROĞLU, Bülent: Roma Usul Hukuku, İstanbul 1980, s. 34; C. 2. 52.7.

${ }^{23}$ UMUR, Ders notlan, s. 203; KASER, s. 275.

${ }^{24}$ DEL GIUDICE, Federico, BELTRANI, Sergio: Nuovo Dizionario Giuridico Romano, 2. Ed., Napoli 1995, s. 145; GUARINO, Antonio: Diritto Privato Romano, Napoli 2001, s. 616 vd.; SANFILIPPO, Cesare: Istituzioni di Diritto Romano, Messina 1996, s. 204; SCHULZ, s. 200; HUVELIN, s. 393.

${ }^{25}$ Ab intestato terimi, vasiyetname yapmadan ölen ve bu sebeple mirası kanuni mirasçılara intikal eden kişi için kullanılmaktaydı., UMUR, Lügat, s. 95.

${ }^{26}$ D. 27. 10. 1. pr. Ulpianus (Sabinum, lib. 1); C. 5. 70; SOHM, s. 492; KASER, s. 277; SCHULZ, s. 200; VOLTERRA, s. 129; LEE, s. 90; TALAMANCA, s. 172.
} 
Roma'da müsrif olarak kabul edilen kişiler tam ehliyetsiz sayılmamaktaydılar. Müsrifin hukuki durumu, yedi on dört yaş arasındaki impubesin hukuki durumuna benzemekteydi. Müsrifin kendi lehine yaptığ kazandırıcı işlemlerin geçerli olmasına karşın, kendini borç altına sokan işlemler için kayyımın rızasına ihtiyaç bulunmaktaydı. Kayyım, rızasını, ehliyetsizin bir hukuki işlem yapmasından önce bildirebileceği gibi, işlem yapildıktan sonra da icazetini verebilirdi ${ }^{27}$. Müsrif ile kayyım arasındaki ilişki kendiliğinden sona ermezdi. Müsrif üzerine atanan kayyım ancak magistranın onayı ile görevden alınabilirdi ${ }^{28}$.

\section{III - Kayyımın Hukuki Sorumluluğu}

Kayyımın görevleri ve hukuki sorumluluğu vasininkilere benzemekteydi. Ancak, kayyım, vasinin sahip olduğu kadar geniş bir resmi yetkiye sahip bulunmamaktaydı. Müsriflerin ve akıl hastalarının yapması gereken hukuki işlemleri kayyım onlar adına yapardı, mameleklerini idare ederdi. Yirmi beş yaşından küçüklerin yaptıkları hukuki işlemlerde kayyım da hazır bulunurdu ${ }^{29}$. Örneğin kayyım, gözetimi altındaki akıl hastasının kölesine veya evladına, peculiumun ${ }^{30}$ idaresi için yetki verebilirdi ve tüm işlemleri gözetim altındaki kişi adına yapabilirdi. Bunun yanı sıra, köleyi serbest bırakamazdı veya özgürlüğünü veremezdi.

Severus, M.S. 195 yilında, vasiyetnamede belirtilen durumlar ve acil haller dışında şehir çevresinde bulunan alanlardaki arazilerin kayyımlar tarafından satışını yasaklamıştı. İstisnai durumlarda ise, magistra'nın izni ile işlem yapılması mümkündü. Ancak, mevcut durum hakkında magistra'yı tam olarak bilgilendirmemesi halinde, bu izin dahi kayyımı sorumluluktan kurtarmamaktayd $\imath^{31}$.

D. 27. 9. 1. pr.,Ulpianus (Edictum lib.35.):

"Imperatoris Severi oratione prohibiti sunt tutores et curatores praedia rustica vel suburbana distra here."

"Imparator Severus'un emirnamesi ile, vasilerin ve kayyımların kasaba ve şehir çevresinde bulunan mülkleri satmaları yasaklanmıştır."

Kayyım, gözetimi altındaki kişiyi davada hem davalı hem de davacı olarak temsil ederdi ${ }^{32}$. Kayyım, gözetimi altındaki kişi adına dava

\footnotetext{
${ }^{27}$ UMUR, Ziya: Roma Hukuku Ders Notları, İstanbul 1990, s. 202; VOCI, s. 101; BONFANTE, s. 643; BETTI, s. 71.

${ }^{28}$ SCHULZ, s. 201.

${ }^{29}$ DI MARZO, s. 202.

30) Peculium, kölelere ve aile evlatlarına aile menfaatine iş yapabilme imkanı vermek için malikin rızası altında, köle veya aile evladının kendi kendine elde ettiği bir sermayeydi. Daha sonraki dönemlerde malik, aile evladı veya köleye, kendi mamelekinden ayırdı̆̆ı bir peculium vererek onu işletmesine imkan sağlamaya başlamıştı. UMUR, lügat, s. 154.

${ }^{31}$ BUCKLAND, s. 154

${ }^{32}$ ROBY, s. 122.
} 
açabilirdi, aynı zamanda gözetimi altındaki kişi aleyhine açılan davaları da takip etme yetkisine sahipti.

Iust. Ins. 4. 10. pr.

"Nunc admonendi sumus agere posse quemlibet aut suo nomine aut alieno. Alieno veluti procuratorio tutorio curatorio, ...."

"Bir kimse, gerek kendisi için, gerekse başkası namına dava ikame edebilir. Başkası namına, vekil olarak, vasi olarak ve kayyım olarak dava açabilir."

Kayyım, gözetimi altında bulunan kişinin mallarını iyi bir şekilde, zarara uğratmadan idare etmek yükümlülüğü altındadır. Bunun yanında, gözetim altında bulunan kişide, görevi nedeniyle kayyımın yaptığı masrafları ve varsa zararları tazmin etme borcu altına girmekteydi. Kayyımın, malların idaresinde ve borçların ifasında gösterilmesi gereken dikkat ve özeni göstermemesi halinde, hatası veya hilesi nedeniyle oluşan zararlardan sorumlu olduğu kabul edilmekteydi. Genellikle bu dava, actio negotorum gestorum, vekaletsiz iş görme hükümlerine göre açılmaktaydı ${ }^{33}$. Kayyım, işin idaresi nedeniyle tüm kusurlarından (omnis culpa) sorumluydu ve iyi bir aile reisi gibi hareket etmesi gerekliydi. Bu nedenlerden biri ile kayyıma karşı dava açılması halinde, kayyım da bu davaya karşı bir karşılık dava açabilirdi ${ }^{34}$. Kayyımın, gözetimi altında bulunan kişiye karşı actio contraria açarak zararını veya mamelekin idaresi sırasında yaptığı zaruri ve faydalı masrafların isteyebilirdi ${ }^{35}$.

D. 27.4. 1.2., Ulpianus (Edictum, lib. 36)

"Sed et si curator sit vel pupilli vel adulescentis vel furiosi vel prodigi, dicendum est etiam his contrarium dandum"

"Actio contraria, küçüğe veya akıl hastasına veya müsrife atanan kayyımlara da tanınmaktadır."

Kayyım, bu göreve atanđı̆̆ı zaman, gözetim altındaki kişinin mallarının korunması açısından belli bir teminat gösterme borcu altına girerdi. Ancak, consul, praetor veya vali tarafından atanan kayyımların böyle bir teminat gösterme yükümlülüğü bulunmamaktaydd ${ }^{36}$.

D. 27. 10.7.2., Iulianus (Digestorum, lib. 21)

"Cum dementis curatorem, quia satis non dederat et res male administraret, proconsul removerit a bonis alimque loco eius substituerit curatorem, ed hic posterior, cum nec ipse satisdedisset,..."

\footnotetext{
${ }^{33}$ D. 3. 5. 5., Ulpianus (Edictum, lib. 10); RADO, Türkan: Roma Hukuku Dersleri Borçlar Hukuku, İstanbul 1982, s. 171; TALAMANCA, s. 174.

${ }^{34}$ D. 27. 4. 1. 2., Ulpianus (Edictum, lib. 36); THOMAS, s. 57; KASER, s. 276.

35 RADO, s. 172.

${ }^{36}$ Gaius 1. 199. , 200; Iust. Ins. 1. 24. pr.
} 
"Proconsul, akıl hastası olan bir kişinin kayyımını, gerekli teminatı vermemesi ve malı kötü bir şekilde yönetmesi nedeniyle, kayyımı görevinden alarak yerine yeni kayyım atardı."

Kayyımın belli kişilere ve magistralar aracılı̆̆ı ile atanması, kayyımlığın bir kamu görevi olduğunu akla getirmektedir. Kayyım, yüklendiği bu görev dolayısıyla, kendi kusuru sonucu ortaya çıkan zararları da gidermekle yükümlüydü.

Iust. Ins. $1.25 \mathrm{pr}$.

“... cura possunt excusari exemplo ceterorum munerum: nam et tutelam et curam placuit publicum munus esse."

“...diğer kamu hizmetlerinde olduğu gibi, ...... kayyımlık bir kamu hizmetidir."

\section{IV - Kayyımlık İlişkisinin Sona Ermesi}

Kayyım ve gözetim altında bulunan kişi kayyımlık ilişkisinin taraflarını oluşturmaktaydı. Bu ilişkinin taraflarından birinin ölmesi halinde kayyımlık doğal olarak sona ererdi. Müsrif üzerindeki kayyımlık, müsrifin ölümü veya üzerindeki hacir kararının kaldırılması ile sona ererdi. Yirmi beş yaşından küçük için atanan kayyımın görevi de, küçüğün yirmi beş yaşını doldurması ile otomatik olarak sona ererdi.

Kayyımın belli bir dönem için seçilmesi mümkün görülmekteydi. Kayyım, seçildiği dönem içinde yetkili kılınmaktaydı ve bu dönemde yaptı̆̆ hukuki işlemler nedeniyle doğan zararlardan sorumlu tutulmaktaydı. Kayyım için belirlenen görev süresinin dolması ile gözetim altındaki kişi ile kayyımın arasındaki ilişki kendiliğinden son bulurdu.

Kayyım, çok yaşlı veya hasta olduğu durumlarda kayyımlık görevinden feragat edebilirdi. Ayrıca, kayyımın ne kadar çok çocuğu varsa, sorumluluğunun da o kadar fazla olacağı düşünüldüğüunden, Roma'da üç, İtalya'da dört ve diğer yerlerde beşten fazla çocuğu olan kayyımların bu görevlerinden feragat etmeleri mümkün olmaktayd ${ }^{37}$. Kayyımın feragat etmesi ile de, kayyım ile gözetim altındaki kişi arasındaki ilişki sona ererdi.

Bir kayyım, gözetim altında bulunan kişinin mamelekini gerektiği gibi yönetmezse, mameleki zarara uğratıcı tasarruflarda bulunursa veya yapması gereken işleri tam olarak ve zamanında yapmazsa, kayyımın iyiniyetli olduğu düşünülemezdi. Kayyımın bu şekilde görevine devam etmesi gözetim altındaki kişi açısından büyük sakıncalar doğurmaktaydı. Bu nedenle, bu şekilde hareket ettiği ispatlanan kayyımın kayyımlığı sona ererdi.

\footnotetext{
${ }^{37}$ Iust. Ins. 1. 25. pr.
} 


\section{BIBLIYOGRAFYA}

BORKOWSKI, Andrew: Textbook on Roman Law, 2. Ed., United Kingdom, 2001

BONFANTE, Pietro: Corso di Diritto Romano, Vol.: 1, Milano 1963

ÇELEBİCAN, Özcan: Roma Hukuku, Ankara 1997

DEL GIUDICE, Federico,

BELTRANI, Sergio: Nuovo Dizionario Giuridico Romano, 2. Ed., Napoli 1995

DI MARZO, Salvatore: Roma Hukuku (Çeviren: Ziya UMUR), İstanbul 1954

ERDOĞMUŞ, Belgin, TAHİROĞLU, Bülen: Roma Usul Hukuku, İstanbul 1980

FAYER, Carla: La Famiglia Romana Aspetti Giuridici ed Antiquari, Parte Prima, Roma 1994

GUARINO, Antonio: Diritto Privato Romano, Napoli 2001

GÜNAL, Nadi: Roma Hukuku'nda Varolmayan Bir Borcun İfası Nedeniyle Sebepsiz Zenginleşme (Condictio Indebiti), Ankara 1996

HUVELIN, Paul: Cours Élémentaire de Droit Romain, Paris 1927

KASER, Max: Roman Private Law (Translated by: Rolf DANNENBRING), Durban 1965

LEE, R.W.: The Elements of Roman Law, London 1946

KOSCHAKER, Paul, AYİTER, Kudret: Roma Hususi Hukukunun Ana Hatları, Ankara 1975

RADO, Türkan: Roma Hukuku Dersleri Borçlar Hukuku, İstanbul 1982

ROBY, Henry John: Roman Private Law in Times of Cicero and of Antonines, New Jersey 2000

SANFILIPPO, Cesare: Istituzioni di Diritto Romano, Messina 1996

SCHULZ, Fritz: Classical Roman Law, Oxford 1969

TALAMANCA, Mario: Istituzioni di Diritto Romano, Milano 1990

THOMAS, J.A.C.: The Institutes of Iustinian, Oxford 1975

UMUR, Ziya: Roma Hukuku Ders Notları, İstanbul 1990

: Roma Hukuku Lügat1, İstanbul 1983 (Lügat)

VOCI, Pasquale: Istituzioni di Diritto Romano, Milano 1996

VOLTERRA, Edoardo: Corso di Istituzioni di Diritto Romano, Roma 1995 